\title{
Sandstorm erosion testing of anti-reflective glass coatings for solar energy applications
}

\author{
Florian Wiesinger ${ }^{\mathrm{a}, *}$, Gema San Vicente ${ }^{\mathrm{b}}$, Aránzazu Fernández-García ${ }^{\mathrm{c}}$, \\ Florian Sutter $^{\mathrm{a}}$, Ángel Morales ${ }^{\mathrm{b}}$, Robert Pitz-Paal ${ }^{\mathrm{d}}$ \\ $5 \quad{ }^{a}$ DLR German Aerospace Center, Institute of Solar Research, Plataforma Solar de Almería, \\ Ctra. Senés, km.4, P.O. Box 39, 04200 Tabernas, Almería, Spain \\ ${ }^{b}$ CIEMAT-Plataforma Solar de Almería, Avd. Complutense 40, 28040 Madrid, Spain \\ ${ }^{c}$ CIEMAT-Plataforma Solar de Almería, Ctra. Senés, km.4, P.O. Box 22, 04200 Tabernas, \\ Almería, Spain \\ ${ }^{d}$ DLR German Aerospace Center, Institute of Solar Research, Linder Höhe, 51147 Cologne, \\ Germany
}

\begin{abstract}
Components for concentrating solar power applications can suffer from optical performance loss due to their permanent exposure to the environment. There is still lack of experience regarding the destructive effects of sand- and duststorms on glass envelope materials for receiver tubes of parabolic-trough collectors for concentrating solar power (CSP) plants. So far no accelerated aging guideline is formulated yet to account for the performance loss of optical components due to particle erosion to a realistic extent. Within this study 4 different antireflective (AR) coatings deposited on borosilicate glass are subjected to an artificial sandstorm test and their resistance towards erosion is evaluated. An uncoated borosilicate glass is also tested as reference. Noticeable differences were obtained depending on the type of coating. Microscope analysis and light transmission measurements in the spectrophotometer were undertaken and it could be concluded that the selection of an AR coating should not only be based on the initial optical performance but also in accordance with meteorological data, especially when erosive sandstorms are expected for the chosen site of the CSP plant.

Keywords: CSP technology, anti-reflective coating, glass envelope tube, accelerated aging, sand erosion
\end{abstract}

*Corresponding author
Preprint stbmitted to Journal of ETEX Templates
Emait address: florian.wiesinger@alr.de (Florian Wiesinger)

January 24, 2018 


\section{Nomenclature}

\begin{tabular}{|c|c|c|}
\hline Symbol & Description & Unit \\
\hline$A$ & sample area & $\mathrm{cm}^{2}$ \\
\hline$c$ & volumetric mass concentration & $\mathrm{mg} \mathrm{m}^{-3}$ \\
\hline$m$ & impacting sand mass & $\mathrm{g}$ \\
\hline$S q$ & root mean square height of surface & $\mu \mathrm{m}$ \\
\hline$t$ & testing time & $\mathrm{s}$ \\
\hline$v$ & wind velocity & $\mathrm{m} \mathrm{s}^{-1}$ \\
\hline$\gamma$ & cumulated sand mass per area & $\mathrm{g} \mathrm{cm}^{-2}$ \\
\hline$\Theta_{i}$ & radiation incidence angle & $\circ$ \\
\hline$\lambda$ & wavelength & $\mathrm{nm}$ \\
\hline$\tau$ & transmittance & $\%$ \\
\hline$\tau_{s, h}$ & $\begin{array}{l}\text { solar weighted hemispherical transmittance at } \\
\lambda=[280,2500] \mathrm{nm} \text { and } \Theta_{i}=8^{\circ}\end{array}$ & $\%$ \\
\hline
\end{tabular}

\section{Subscript Description}

$h \quad$ subscript indicating hemispherical value

$s \quad$ subscript indicating solar weighted value after [1]

$\begin{array}{ll}\text { Acronyms } & \text { Description } \\ \text { AR } & \text { Anti-reflective } \\ \text { CSP } & \text { Concentrating Solar Power } \\ \text { MTES } & \text { Methyltriethoxysilane } \\ \text { TEOS } & \text { Tetraethylorthosilicate } \\ \text { SDS } & \text { Sand- and Duststorm }\end{array}$

continued on next page 


\section{Acronyms Description}

SEM Scanning Electron Microscope

SSC Sand- and Duststorm Chamber

US Ultra Sonic 


\section{Introduction}

In order to perform a reasonable yield analysis for concentrating solar power (CSP) plants, it is of crucial importance to determine all the relevant parameters that are affecting the electrical energy output. Energy conversion processes are limited in their efficiency due to several constraints. Losses can be of optical nature, because of heat losses or further effects like operation strategy or parasitic energy [2]. It is important to note, that all those variables can change over time and thereby have a significant impact on the annual electricity yield of a CSP plant. Performance forecasts over the complete component lifetime are necessary in order to assess the economic benefit of the system as a whole.

${ }_{25}$ Typically, the components that are going to be used for CSP installations are subjected to accelerated aging tests which are especially tailored to meet the conditions to be expected during their lifetime [3, 4]. Many of those testing procedures are already formulated as standards, like the salt spray test according to ISO 9227 standard [5] for marine environments, the ISO 11507 standard [6] 30 for long-term UV-radiation and cyclic condensation or the IEC 61215 standard test 10.11 [7] for the simulation of thermal cycles. There is no standard available yet to conduct a reasonable testing to simulate erosion effects on optical components for CSP applications caused by sand- and duststorms (SDS). However, some institutes provide fundamental experimental results in this topic. It should be pointed at the work by Sansom et al. [8], who investigated the erosion behavior of different sand types at changing impact velocities for silverd- glass reflector samples. Also, the group around Karim [9] experimentally determined the influence of most of the important parameters like the impact velocity, the impact angle and the sand particle properties on the erosion intensity for solar glass mirrors. An earlier study of the current group compared artificial aging results with naturally eroded reflector samples, that were exposed in the field [10]. Furthermore worth to be mentioned are the works by Houmy et al. [11] and Mahdaoui et al. [12. All the fore-cited research dealt with erosion on glassor aluminum reflectors but no study is known that has a closer look on the ef- 
fects of SDS on the anti-reflective (AR) coatings of glass envelope tubes which present an essential part for parabolic trough solar collectors, though [13].

The AR coating applied to the glass cover is sensitive towards mechanical wear. The low refractive index condition which has to be satisfied by the AR coating to obtain the maximum light transmission on glass, makes it necessary to use 50 a highly porous material $\left(\mathrm{SiO}_{2}\right)$ [14. The mechanical resistance of this porous coating is considerably lower than the same material dense coating as the pores are filled with air and the bonds between substrate and coating and among the silica material in the coating are weaker. Thus, it is reasonable to assume that damages on the coating might be more intensive than on the uncoated glass.

55 Therefore, special care must be taken for the realistic selection of artificial testing conditions.

The sol-gel dip-coating technology is the most used method for producing AR layers on large glass areas. This process has the ability to coat both sides on the substrate simultaneously and it is the state of the art method to coat the ${ }_{60}$ solar glass envelope tubes for parabolic-trough collectors (PTC) at both sides. The porous structure of the film can be achieved by using a colloidal solution [15] or by adding a "porogen" material to the polymeric sol-gel solution [16]. This compound is removed during the heat treatment, generating pores inside the polymeric silica films.

${ }_{65}$ In this paper, different AR coatings prepared by using polymeric solutions are tested in a sandstorm chamber in order to study the resistance under extreme desertic conditions. 


\section{Methodology}

In this section the preparation of the AR coated samples is described as well as the used instruments to characterize them during testing. Furthermore the artificial erosion procedure is explained.

\subsection{Sample preparation}

In this work borosilicate flat glass substrates with different AR coatings were investigated. Before coating, the $4 \mathrm{~mm}$ thick glass samples (dimensions: $7 \times 4 \mathrm{~cm}^{2}$ ) were cleaned with soaped water and rinsed with distilled water. The polymeric solution was prepared by mixing tetraethylorthosilicate (TEOS), methyltriethoxysilane (MTES), water and ethanol using a molar ratio for alkoxide:water:ethanol of $1: 5: 48$, respectively. Hydrochloric acid was used as a catalyst and Triton X-100 as pore generator. The solutions were applied on the substrate on both sides by dip coating. The withdrawal rate was $20 \mathrm{~cm} \mathrm{~min}^{-1}$ and afterwards the samples were introduced in the oven for being heat treated at $500^{\circ} \mathrm{C}$ for 15 minutes. Three different solutions were prepared varying the concentration of Triton X-100 (porogen material). One of them with complete absence of Triton X-100, another with a concentration of $10 \mathrm{~g} \mathrm{l}^{-1}$, and the last one with $15 \mathrm{~g} \mathrm{l}^{-1}$. Finally, some samples prepared with $15 \mathrm{~g} \mathrm{l}^{-1}$ were additionally treated with an hydrophobic commercial solution. Sample B5 corresponds to a borosilicate glass with neither coating nor treatment. Tab1 1 makes clear the nomenclature of the prepared samples.

Tab. 1: Nomenclature and preparation procedures of the used sample material.

\begin{tabular}{cc}
\hline Sample ID & Preparation steps \\
\hline AR1 & No Triton X-100 \\
AR2 & $10 \mathrm{~g} \mathrm{l}^{-1}$ Triton X-100 \\
AR3 & $15 \mathrm{~g} \mathrm{l}^{-1}$ Triton X-100 \\
AR4 & $15 \mathrm{~g} \mathrm{l}^{-1}$ Triton X-100 + hydrophobic treatment \\
B5 & uncoated borosilicate glass \\
\hline
\end{tabular}




\subsection{Sample characterization methods}

The samples were characterized before and after each testing by optical transmittance measurements and optical microscopy. The hemispherical transmittance, $\tau_{s, h}\left([280,2500] \mathrm{nm}, 8^{\circ}, \mathrm{h}\right)$ was measured with a spectrophotometer

2.3. Details on the sandstorm chamber (SSC)

The erosion setup employed in the experiments was a closed loop wind tunnel with particle injection. Fig 1 shows photographs of the SSC and its sample compartment. The original prototype was a ST200 from the company ITS. It has been equipped with an ultrasonic wind sensor, type FT702LT/D from FT Technologies LTD to monitor the wind velocity inside the SSC. As test dust, Arizona quartz dust from KSL Staubtechnik GmbH with a particle size distribution after ISO 12103-1 A4 (maximum particle diameter $<352 \mu \mathrm{m}$ ) has been used. For the determination of the particle concentration a gravimetric measurement principle was used. Therefore a bypass of the main airflow was leading to an air sampling pump, type TUFF from Casella. This device enables 


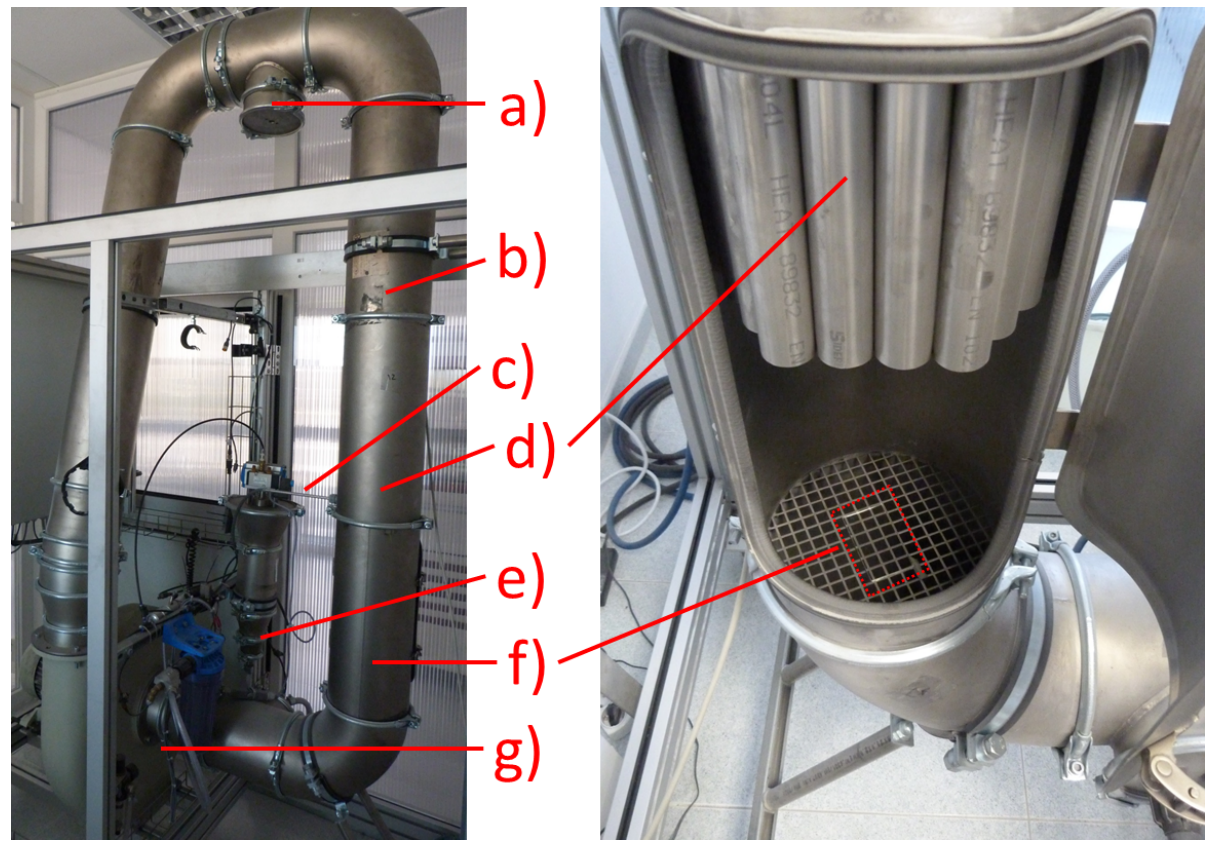

Fig. 1: Modified prototype sandstorm chamber ST200 and its sample compartment: a) connection for the ultrasonic wind sensor (was only attached for velocity calibration), b) particle mixer (inside tube), c) bypass pipe for c-measurement, d) flow rectifier, e) particle injection, f) sample compartment (glass sample indicated by dashed rectangle), g) ventilator.

the filtering of the particles in the airflow and by the determination of the mass difference of the filter before and after the testing and the used airmass flow, the average volumetric particle concentration $c$ can be calculated. Even though the dust concentration could not be controlled accurately, it could be measured by the TUFF and be taken into account for the analysis. The quantity of cumulated sand mass per area, named $\gamma$ in $\left[\mathrm{g} \mathrm{cm}^{-2}\right]$ combines the averaged dust concentration $c$ and the testing time $t$ with the wind velocity $v$ and is therefore the all-encompassing parameter for advancing erosion. It is calculated with the formula:

$$
\gamma=\frac{m}{A}=c \cdot v \cdot t
$$

where $m$ is the impacting sand mass and $A$ is the area of the sample. 


\subsection{Testing and cleaning procedure}

One sample from each type of coating was investigated for two different velocities, namely 12.2 and $17.1 \mathrm{~m} \mathrm{~s}^{-1}$ and four consecutive erosions treatments were applied to every sample, lasting 10 minutes each. The setpoint for dust concentration was $100 \mathrm{mg} \mathrm{m}^{-3}$ as it has been measured in a field study [19] and comparable values have been used for accelerated aging experiments already [20, 8. However this setpoint was constantly exceeded by a factor of around 2 and 4 for the testing at 12.2 and $17.1 \mathrm{~m} \mathrm{~s}^{-1}$, respectively. Since it was the minimal setpoint for the concentration, $c$ could not be decreased further. Subsequent sample characterizations took place in order to observe changes of the optical transmittance or the occurrence of microscopic defects. Before performing the optical characterization, the sample had to be cleaned. The execution of the cleaning procedure has high demands for its reproducibility since even small irregularities during its application might lead to systematic errors of the interpretation of the respective $\tau_{s, h}$ data. The decision was made for an ultrasonic (US) cleaning method. Therefore, the sample was placed in a beaker, leaned against the inner wall under an angle of around $45^{\circ}$, so that the tested surface was facing downwards. The beaker was filled with ethanol and placed in an ultrasonic bath of type PCE-UC 100 from PCE Ibérica S.L. (Tobarra, Spain) for 60 minutes. A manual cleaning procedure was refused because of its poor reproducibility and the high sensitivity of the coatings towards cleaning by hand.

There was an additional water jet cleaning applied in the end, to check on the effectiveness of the ultrasonic cleaning. The water jet cleaning, as depicted in Fig 2 is a state of the art cleaning method for reflectors and receiver tubes employed in solar power plants. A cleaning method study by Navarro and Martinez [21] described it as the most appropriate one, as well. The parameters of the water jet device were directly taken from their work which represents also the manufacturers recommendations and can be seen in table 2. The treatment lasted around 3 seconds for each sample and is representative for real plant maintenance operations. 


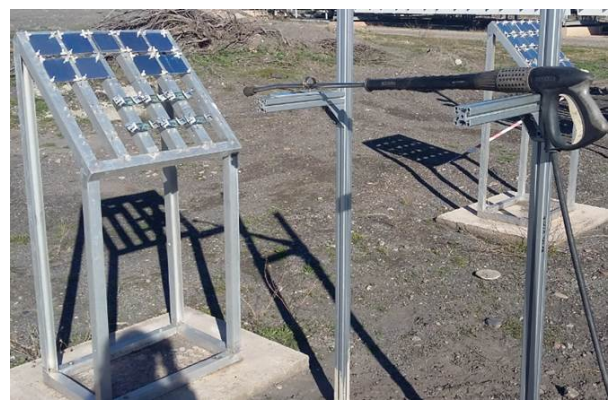

Fig. 2: Water jet cleaning setup.

Tab. 2: Water jet cleaning parameters.

\begin{tabular}{cc}
\hline parameter & value \\
\hline Distance & $50 \mathrm{~cm}$ \\
Water pressure & $20 \mathrm{bar}$ \\
Nozzle aperture & ca. $25^{\circ}$ \\
Fluid & demineralized water \\
\hline
\end{tabular}




\section{Results and Discussion}

\subsection{Initial transmittance}

Fig 3 shows the transmittance spectra ot the five different samples before testing. The graph depicts the hemispherical transmittance $\tau_{\lambda, h}$ for the complete measured wavelength spectrum and the inset gives a more accurate view on the high transmittance region. In the complete range, the sample AR3 exhibits the highest transmittance with a maximum of $\tau_{\lambda, h}$ of $99.2 \%$ at $610 \mathrm{~nm}$, while sample B5, the uncoated borosilicate glass, exhibits $\tau_{\lambda, h}$ values around $92 \%$ for $\lambda$ between 410 and $2100 \mathrm{~nm}$. It is clearly seen, that the application of an AR coating prepared from solutions 1,2 , or 3 significantly enhances the transmittance over the whole spectrum and most particularly in the visible wavelength range. The calculated values of $\tau_{s, h}$ for each spectrum are given in Tab 3 . Highest $\tau_{s, h}$-and therefore most suitable for CSP applications at first- was obtained for sample AR3 with 97.0\%, followed by AR2, AR4 and AR1 in this succession. In case of the AR3 coating, $\tau_{s, h}$ could be increased about $4.9 \%$ in comparison to the uncoated B5 sample.

Tab. 3: Values of $\tau_{s, h}$ for all the samples before testing in $\%$.

\begin{tabular}{|c|c|c|c|c|c|}
\hline & AR1 & AR2 & AR3 & AR4 & B5 \\
\hline$\tau_{s, h}$ & $94.1 \pm 0.1$ & $96.5 \pm 0.0$ & $97.0 \pm 0.0$ & $96.0 \pm 0.1$ & $92.1 \pm 0.0$ \\
\hline
\end{tabular}

These results are consistent with the composition of the solution which was employed to prepare each sample. The sample AR1 which shows only a low increase in $\tau_{s, h}$ is prepared from a solution where the porosity marker is not added. Hence, this sample corresponds to a dense silica coating, with a higher refractive index than the porous films and consequently a lower $\tau_{s, h}$ improvement is produced. A similar argumentation follows for the samples AR2 and AR3 where the first one is prepared with a lower concentration of Triton X-100 and therefore a coating less porous, with higher refractive index, is obtained which leads to a lower $\tau_{s, h}$. Triton X-100 acts as a sacrificial organic template. This 


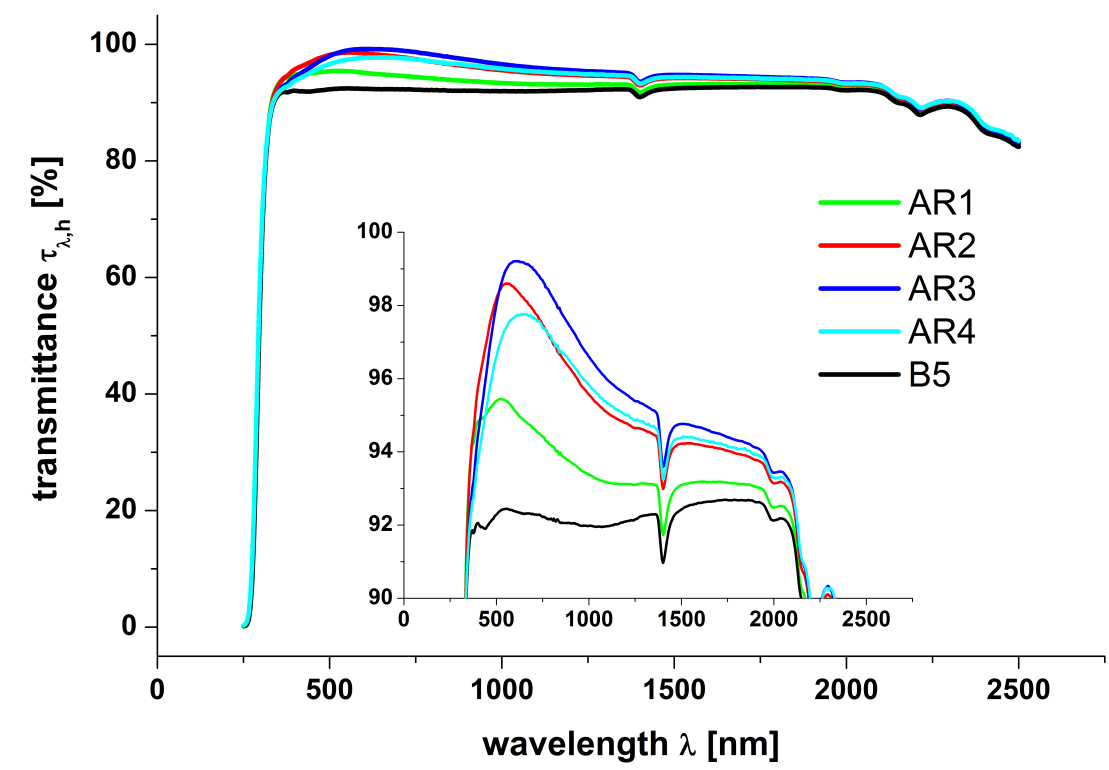

Fig. 3: Hemispherical transmittance spectra of the five different samples, four AR coated and the uncoated borosilicate glass.

compound is removed during the heat treatment creating porosity by leaving voids in the coating [22]. Concerning sample AR4, after the AR deposition, in the same conditions of AR3, a hydrophobic treatment was applied on the sample which fills a part of the porous structure, decreasing the high $\tau_{s, h}$ value which had been obtained by the application of $20 \mathrm{~g} \mathrm{l}^{-1}$ Triton X-100 in sample AR3, from $97 \%$ to $96 \%$.

\subsection{Artificial erosion in the $S S C$}

Fig 4 shows the microscope pictures of samples B5 and AR3 after 10 minutes and 40 minutes of testing at $v=12.2 \mathrm{~m} \mathrm{~s}^{-1}$. These pictures provide clear evidence of the ongoing erosion on both samples. The top pictures a) and b) represent the surface of the uncoated borosilicate glass (B5 sample). Already after 10 minutes of testing, a lateral crack with material chipping has been formed and also plastic deformations can be observed all over the picture in 

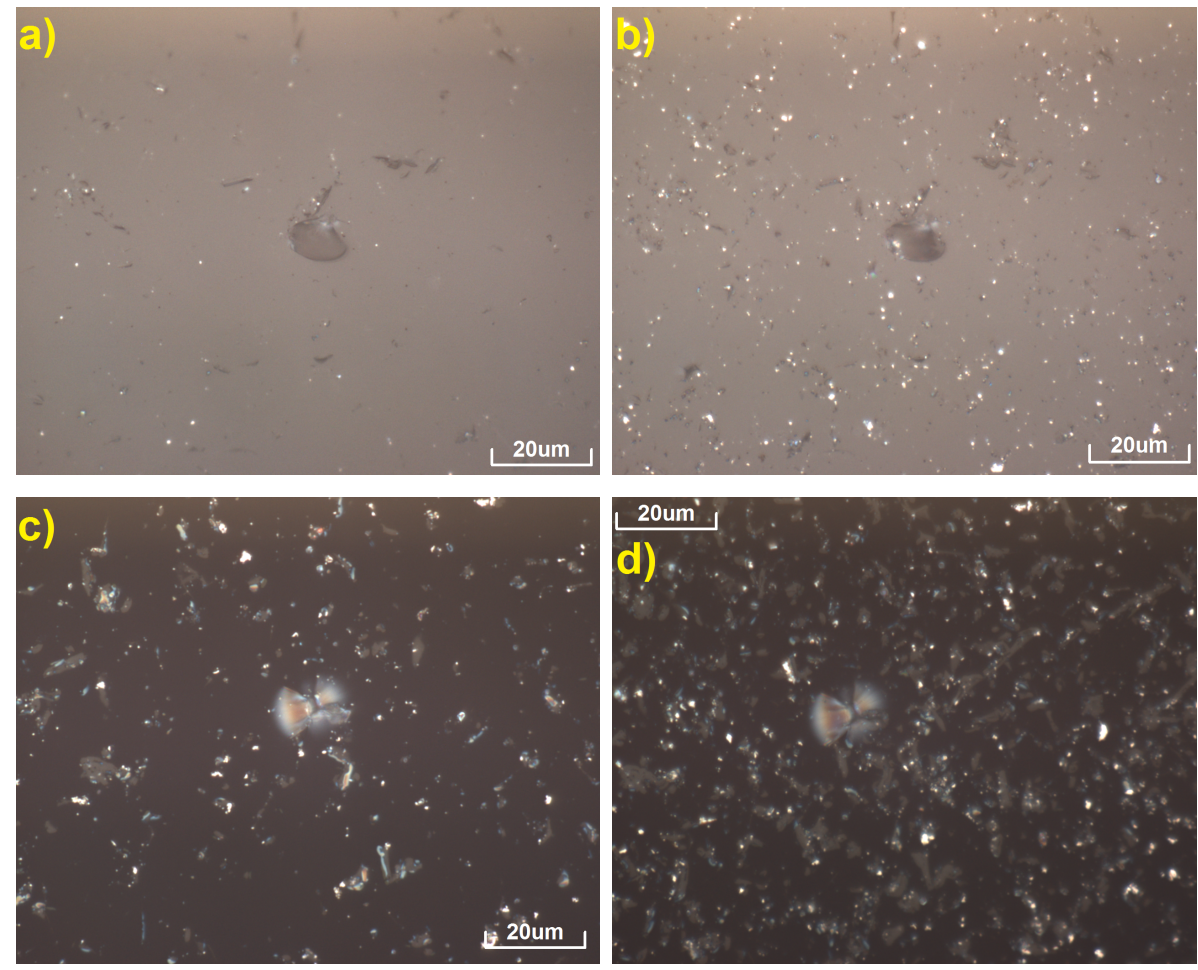

Fig. 4: Microscope pictures of the samples after treatment in the SSC at $v=12.2 \mathrm{~m} \mathrm{~s}^{-1}$; uncoated borosilicate glass (B5) for a) 10 minutes and b) 40 minutes and sample AR3 for c) 10 minutes and d) 40 minutes.

Fig 4 (a). These plastic deformations are typical for impacts with energy below a certain threshold where brittle materials show ductile behavior [23. With ongoing testing, the density of the plastic deformation spots increases and dust particles tend to adhere in the produced craters (see Fig $4(\mathrm{~b})$ ). While the dust is effectively removed from the major parts of the undamaged surface by the US cleaning method, it still adheres to the regions where the surface has been damaged due to the erosion treatment. The light scattering at the deformation sites itself and in addition at the therein deposited particles is assumed to reduce $\tau_{s, h}$ with ongoing testing intensity. For the sample AR3, after 10 minutes testing a lateral crack can be observed as well (see Fig 4 (c)). Here a material loss due to chipping did not take place so far as this process is probably hindered by the AR 
coating 24]. Moreover, a coating delamination takes place on the spots where

(see Fig $5(\mathrm{~b})$ ). The $\tau_{s, h}$ of AR2 and AR3 samples dropped below the $\tau_{s, h}$ of the AR1 and AR4 when sandstorm testing advances for $\gamma>0.8 \mathrm{~g} \mathrm{~cm}^{-2}$. This could be explained by the dust deposition in the generated defects of the porous coating of type AR2 and AR3. This effect seems to be less present for 220 sample type AR1, as it is denser than AR2 and AR3, and furthermore more resistant. For sample B5, the absence of the AR coating could be responsible for this circumstance. Like at the lower velocity, the sample AR4 performs the best. Similar results were obtained by Pop et al. [25] who investigated the durability of AR coatings for PV modules when subjected to abrasion. The 
coating developed by their group did initially perform worse than a traditional one but did show a higher durability leading to a transmittance gain in 7 out of 10 outdoor test site campaigns. The highest initial optical performance is correlated to the largest degradation because this optical performance is caused by a highly porous coating (low refractive index) which is contradicting to the 230 retaining of properties such as hardness, adhesion, etc. [26]. Also Klimm et al. 27. stated that depending on the environmental conditions, the different surface structures and AR coatings may turn non-effective and $\tau_{s, h}$ may decrease below the level of unstructured or uncoated glass. 

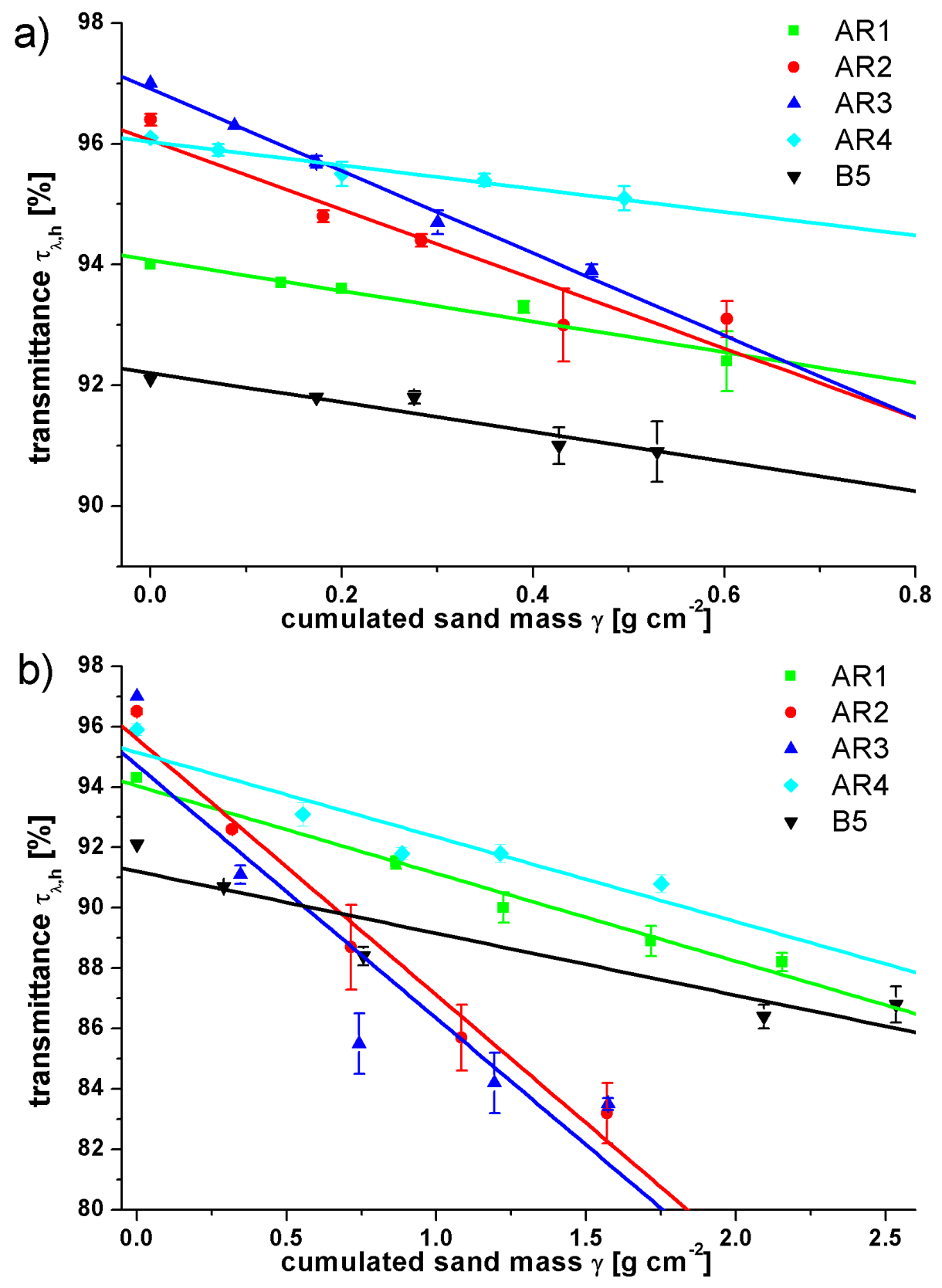

Fig. 5: $\tau_{s, h}$ over progressive SDS testing at a) $v=12.2 \mathrm{~m} \mathrm{~s}^{-1}$ and b) $v=17.1 \mathrm{~m} \mathrm{~s}^{-1}$. Note the different axis ranges for $\gamma$ and $\tau_{s, h}$ in both graphs. 
Tab. 4: slope values in $\left[\% /\left(\mathrm{g} \mathrm{cm}^{-2}\right)\right]$ of the linear fits from Fig 5

\begin{tabular}{cccccc}
\hline$v$ & AR1 & AR2 & AR3 & AR4 & B5 \\
{$\left[\mathrm{m} \mathrm{s}^{-1}\right]$} & & & & & \\
\hline 12.2 & $-2.54 \pm 0.34$ & $-5.74 \pm 1.08$ & $-6.80 \pm 0.37$ & $-1.93 \pm 0.24$ & $-2.45 \pm 0.46$ \\
17.1 & $-2.90 \pm 0.25$ & $-8.48 \pm 0.80$ & $-8.38 \pm 1.90$ & $-2.80 \pm 0.60$ & $-2.05 \pm 0.47$ \\
\hline
\end{tabular}

For a better assessment of the resistance towards reflectance loss during SDS testing, a linear fit was applied to the data from Fig 5 and added to the data points. The slope of the fitted lines with the respective uncertainty can be read out from Tab. The unit of these values is $\left[\% /\left(\mathrm{g} \mathrm{cm}^{-2}\right)\right]$ and it can be understood as an erosion intensity factor. It describes how fast $\tau_{s, h}$ is decreasing with increasing $\gamma$. It becomes obvious, that samples AR2 and AR3 are the most sensitive ones when subjected to the applied SDS test. For the testing at $v=12.2 \mathrm{~m} \mathrm{~s}^{-1}$, the absolute slope values for both types are in the range of $-(4-7) \% /\left(\mathrm{g} \mathrm{cm}^{-2}\right)$, while it is only $-(2-3) \% /\left(\mathrm{g} \mathrm{cm}^{-2}\right)$ for samples of type AR1, AR4 and B5. An increase of $v$ to $17.1 \mathrm{~m} \mathrm{~s}^{-1}$ leads also to an increase of the erosion intensity, thus to an increase in absolute slope values. This change 245 is more pronounced for sample type AR2 and AR3 which now exhibit absolute slope values between $-(6-10) \% /\left(\mathrm{g} \mathrm{cm}^{-2}\right)$ while sample type AR1, AR4 and B5 are still between $-(2-4) \% /\left(\mathrm{g} \mathrm{cm}^{-2}\right)$. For the uncoated sample no increase in erosion intensity was found. It should be noted that similar values of initial $\tau_{s, h}$ for AR2 and AR4 experienced very different erosion rates. As said before, 250 the AR4 sample has an additional hydrophobic layer which partially fills the porous structure and hence follows in a denser and more resistant structure. From this analysis, it can be noted that the optical performance of AR coatings can exhibit quite different characteristics when subjected to SDS testing, and that the optical performance of uncoated borosilicate glass is affected in a similar manner as the comparably softer AR coatings. 


\subsection{Assessment of cleaning efficiency}

In order to prove the effectiveness of the US cleaning method and in order to increase $\tau_{s, h}$ by removing the adhering particles, the water jet clean-

260 $v=17.1 \mathrm{~m} \mathrm{~s}^{-1}$ was finished and the US cleaning was already conducted. The resistivity of the $\mathrm{AR}$ coating towards the water jet treatment was first tested via its appliance on an untested AR3 sample. No significant decrease of the initial $\tau_{s, h}$ was noticed after the water jet cleaning and so it was decided to apply the

\subsection{SEM analysis}

Scanning electron microscope (SEM) pictures that were taken after the SDS treatment at $v=17.1 \mathrm{~m} \mathrm{~s}^{-1}$ and the US cleaning procedure are going to be 285 discussed in the following. In Fig 6 (a), the surface of the B5 sample can be observed. It exhibits a lot of plastic deformations and remaining dust particles 
can still be detected. The surface of the AR3 sample is shown in Fig 6 (b) and it can be seen that it exhibits quite different characteristics regarding its surface morphology. It appears more ragged and it could be argued that the higher surface roughness is responsible for the larger amount of dust particles deposited inside the irregular morphology. Fig 6(c) shows the surface of the AR4 sample. It looks slightly different to the AR3 coating. More islands of plain and less destroyed areas can be seen. Furthermore it appears that less particles are adhering on the surface. This finding is in accordance with the results of the $\tau_{s, h}$ analysis and can be explained by the application of a hydrophobic treatment on the AR4 sample. This treatment provides a surface coating with a low surface energy which should avoid the adhesion of particles on it. The morphology of all samples is clearly affected by the SDS erosion testing, changing from an almost perfectly flat surface before the test to a highly damaged rough one, featuring valleys and peaks afterwards. This circumstance could be quantified by surface texture analysis. The analysis was performed on ten different spots on each sample leading to a root mean square height of the surface $(S q)$ of $0.122 \pm 0.015 \mu \mathrm{m}, 0.113 \pm 0.015 \mu \mathrm{m}$ and $0.100 \pm 0.007 \mu \mathrm{m}$ for samples AR3, AR4 and B5, respectively. $S q$ values have also been measured before the SDS testing and they were around 10 times smaller for all sample types. This also testifies the increasing roughness of the surfaces with ongoing SDS testing. 


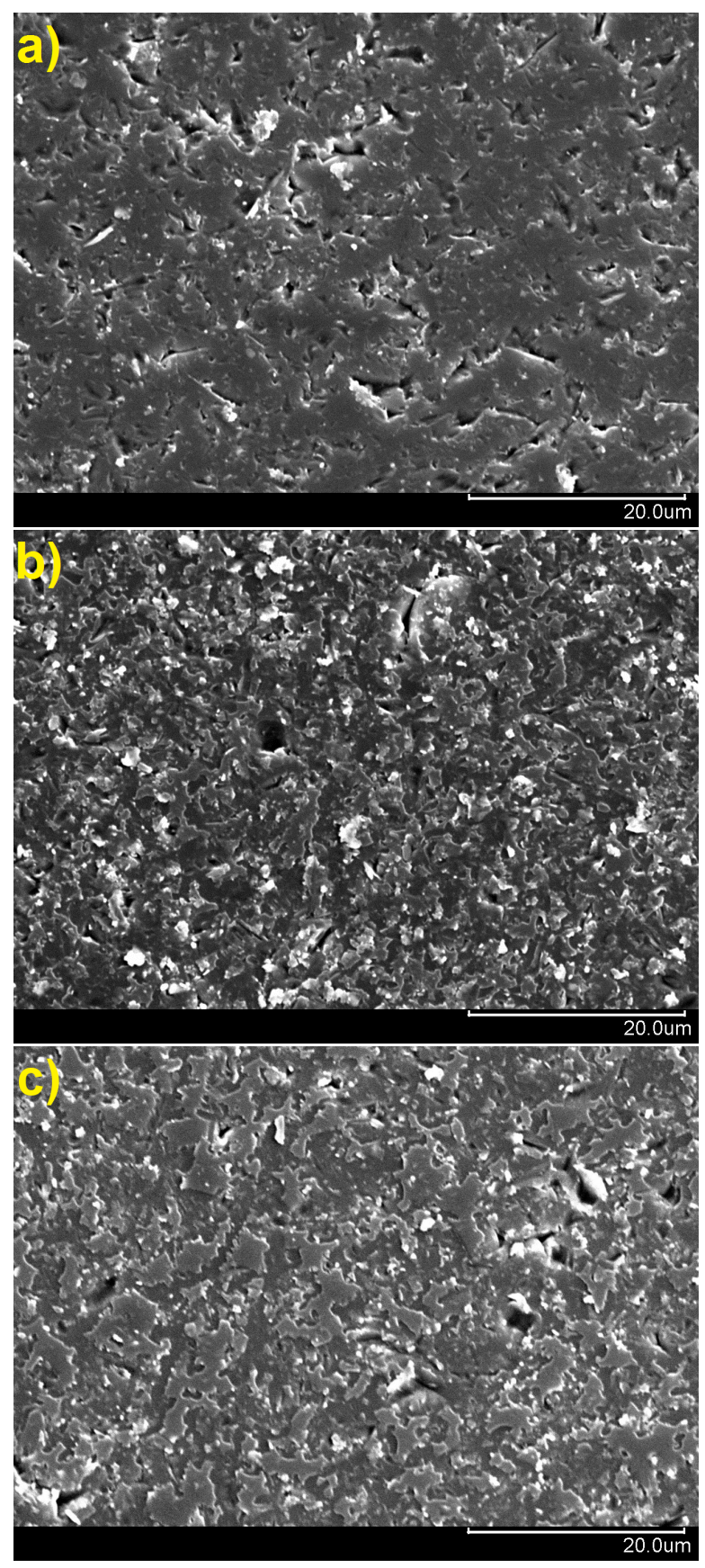

Fig. 6: Scanning electron microscope pictures under $10^{\circ}$ inclination and 2000x magnification after treatment in the SSC at $v=17.1 \mathrm{~m} \mathrm{~s}^{-1}$ of a) sample B5, b) sample AR3 and c) sample AR4. 


\section{Conclusion}

Within this work, it has been shown that AR coatings can enhance the opti-

310

However, the softer mechanical properties of the AR coatings in comparison with glass might lead to a more rapid optical performance loss when the CSP plant site is often plagued by severe sandstorms. The results of the performed experimental SDS simulation are summarized in Tab5. From the initial state increase solar weighted transmittance $\left(\tau_{s, h}\right)$. Furthermore it can be stated that a higher porosity of the AR coating boosts $\tau_{s, h}$ additionally. The hydrophobic coating (applied to sample AR4) slightly reduces the gain of $\tau_{s, h}$ by filling the porous structure of the coating, but reduces the erosion rate considerably. drawn: The AR3 sample that initially exhibits the highest measured $\tau_{s, h}$, shows the strongest loss of $\tau_{s, h}$ after the SDS testing. In the case of AR4, which was produced with the same concentration of porogen, the additional hydrophobic coating reduced the porosity. The durability of the AR3 sample is less than

half as good as the uncoated glass sample B5. The sample AR4, on which an additional hydrophobic coating was applied exhibits an initial $\tau_{s, h}$ value that was slightly lower than for the untreated AR coatings. However, the erosive SDS testing does not show such intensive effects on the performance of AR4 as on the other AR coatings. After the complete SDS procedure, the $\tau_{s, h}$ value

Tab. 5: $\tau_{s, h}$ values in the initial state and after the SDS testing at $v=17.1 \mathrm{~m} \mathrm{~s}^{-1}$ and cleaning in the ultrasonic bath with the respective differences in \%.

\begin{tabular}{cccccc}
\hline$\tau_{s, h}$ & AR1 & AR2 & AR3 & AR4 & B5 \\
\hline $\begin{array}{c}\text { initial state } \\
\text { after SDS testing }\end{array}$ & $94.1 \pm 0.1$ & $96.5 \pm 0.0$ & $97.0 \pm 0.0$ & $96.0 \pm 0.1$ & $92.1 \pm 0.0$ \\
\hline difference & $5.9 \pm 0.3$ & $13.3 \pm 1.0$ & $13.5 \pm 0.2$ & $5.2 \pm 0.3$ & $5.3 \pm 0.6$ \\
\hline
\end{tabular}


330 of the hydrophobic treated AR sample lay significantly higher than those of the untreated ones. It can be concluded, that after a certain outdoor exposure time at high wind velocity and particle concentration, the hydrophobic treated AR coating would outperform the untreated AR coatings. However, this observation must be completed by considering other outdoor parameters (such as 335 UV exposure, humidity, etc.) because the observed trend might change due to the interaction with other degradation mechanisms. Moreover it is reported the importance of applying an AR coating on the glass to improve the optical performance, as the uncoated glass also undergoes a decrease in transmittance due to the SDS testing. 

innovation program under grant agreement Nr. 654479, project WASCOP. The authors want to thank Tomás Jesús Reche Navarro (DLR) and Johannes Wette (DLR) for their support. 


\section{References}

345 [1] ASTM G173, Standard Tables for Reference Solar Spectral lrradiances: Direct Normal and Hemispherical on $37^{\circ}$ Tilted Surface, American Society forTesting and Materials, ASTM International, 2003.

[2] M. Eck, T. Hirsch, J. F. Feldhoff, D. Kretschmann, J. Dersch, A. G. Morales, L. Gonzalez-Martinez, C. Bachelier, W. Platzer, K. J. Riffelmann, M. Wagner, Guidelines for CSP Yield Analysis Optical Losses of Line Focusing Systems; Definitions, Sensitivity Analysis and Modeling Approaches, Energy Procedia 49 (2014) 1318-1327.

[3] F. Sutter, S. Ziegler, M. Schmücker, P. Heller, R. Pitz-Paal, Modelling of optical durability of enhanced aluminum solar reflectors, Sol. Energy Mater. Sol. Cells 107 (2012) 37-45.

[4] A. Fernández-García, M. E. Cantos-Soto, M. Röger, C. Wieckert, C. Hutter, L. Martínez-Arcos, Durability of solar reflector materials for secondary concentrators used in CSP systems, Sol. Energy Mater. Sol. Cells 130 (2014) $51-63$.

[5] ISO 9227, Corrosion Tests in Artificial Atmospheres - Salt Spray Test, International Organization for Standardization, 2006.

[6] ISO 11507, Paints and Varnishes - Exposure of Coatings to Artifical Weathering - Exposure to Fluorescent UV Lamps and Water, International Organization for Standadization, 2013.

[7] IEC 61215, Crystalline Silicon Terrestrial Photovoltaic (PV) Modules - Design Qualification and Type Approval, International Electrotechnical Commission, 2005.

[8] C. Sansom, P. Comley, P. King, H. Almond, C. Atkinson, E. Endaya, Predicting the Effects of Sand Erosion on Collector Surfaces in CSP Plants, Energy Procedia 69 (2015) 198-207. 
[9] M. Karim, S. Naamane, C. Delord, A. Bennouna, Laboratory simulation of the surface erosion of solar glass mirrors, Solar Energy 118 (2015) 520-532.

[10] F. Wiesinger, F. Sutter, A. Fernández-García, J. Reinhold, R. Pitz-Paal, Sand erosion on solar reflectors: Accelerated simulation and comparison with field data, Sol. Energy Mater. Sol. Cells 145 (2016) 303-313.

[11] H. Houmy, A. Khaldoun, H. Ennaceri, A. Ghennioui, A. Ennaoui, Towards a simple sand and dust abrasion and soiling prediction on solar components, IRSEC, Marrakech (2016).

[12] T. Mahdaoui, N. Bouaouadja, M. Madjoubi, C. Bousbaa, Study of the effects of sandblasting on soda lime glass erosion, International review of mechanical engineering 1 (5) (2007) 502-510.

[13] A. Fernández-García, E. Zarza, L. Valenzuela, M. Pérez, Parabolic-trough solar collectors and their applications, Renew. Sustain. Energy Rev. 14 (7) (2010) 1695-1721.

385 [14] G. San Vicente, R. Bayón, N. Germán, A. Morales, Long-term durability of solgel porous coatings for solar glass covers, Thin Solid Films 517 (10) (2009) 3157-3160.

[15] G. Helsch, M. Krzyzak, G. Heide, G. H. Frischat, Adherent antireflection coatings on borosilicate glass for solar collectors, Glass Technology European Journal of Glass Science and Technology Part A 47 (5) (2006) $153-156$.

[16] A. Morales, Sol-gel process for the preparation of porous coatings, using precursor solutions prepared by polymeric reactions, European Patent number EP1329433 (2002).

[17] A. Fernández-García, F. Sutter, L. Martínez-Arcos, C. Sansom, F. Wolfertstetter, C. Delord, Equipment and methods for measuring reflectance of concentrating solar reflector materials, Sol. Energy Mater. Sol. Cells 167 (2017) 28-52. 
[18] ASTM E903-82, Standard Test Method for Solar Absorptance, Reflectance, and Transmittance of Materials Using Integrating Spheres, American Society for Testing and Materials, ASTM International, 1992.

[19] M. Zhao, K. Zhan, Z. Yang, E. Fang, G. Qiu, Q. Wang, Y. Zhang, S. Guo, A. Li, J. Zhang, Characteristics of the lower layer of sandstorms in the Minqin desert-oasis zone, Sci. China Earth Sci. 54 (5) (2011) 703-710.

[20] F. Wiesinger, P. King, F. Pagano, R. Bayon, G. Imbuluzqueta, A.-C. Pescheux, Report on the methodology of accelerated erosion testing for reflectors and absorbers, Technical report, STAGE-STE.

[21] J. N. Navarro, N. Martinez, Receiver tube performance depending on cleaning methods, Energy Procedia 69 (2015) 1529-1539.

[22] G. San Vicente, R. Bayn, A. Morales, Effect of additives on the durability and properties of antireflective films for solar glass covers, J. Sol. Energy Eng. 130 (1) (2008) 011007.

[23] P. J. Slikkerveer, P. C. P. Bouten, F. H. in’t Veld, H. Scholten, Erosion and damage by sharp particles, Wear 217 (2) (1998) 237-250.

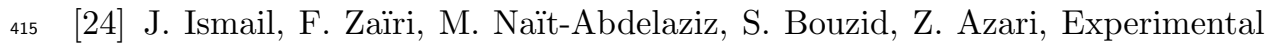
and numerical investigations on erosion damage in glass by impact of smallsized particles, Wear 271 (5) (2011) 817-826.

[25] S. C. Pop, V. Abbaraju, B. Brophy, Y. S. Yang, S. Maghsoodi, P. Gonsalves, A highly abrasive-resistant, long-lasting anti-reflective coating for PV module glass,IEEE 40th Photovoltaic Specialist Conference (PVSC),Denver, Colorado (2014).

[26] Y. Xiao, R. Ma, C. Wang, X. Chen, X. Qiao, X. Fan, High performance hierarchical nanoporous antireflective films by a facile solgel process, RSC Adv. 6 (115) (2016) 113911-113918. 
${ }_{425}^{2}$ [27] E. Klimm, T. Lorenz, K. Weiss, Can anti-soiling coating on solar glass influence the degree of performance loss over time of PV modules drastically?, 28th European PV Solar Energy Conference and Exhibition, Paris (2013). 